\title{
Synthesis of Polypyrrole Coated RGO/S Composite as a Cathode material for Enhanced Lithium-Sulfur Batteries
}

\author{
Haishen Song ${ }^{1,2,3, *}$, Hailiang Yuan ${ }^{1}$, Hezhang Chen ${ }^{1}$, Guorong $\mathrm{Xu}^{1}$, Anping Tang ${ }^{2}$, and Lihua Liu ${ }^{3}$ \\ ${ }^{1}$ School of Chemistry and Chemical Engineering, Hunan University of Science and Technology, \\ Xiangtan 411201, Hunan, China \\ ${ }^{2}$ Key Laboratory of Theoretical Organic Chemistry and Functional Molecule of Ministry of Education; \\ Hunan Provincial Key Lab of Advanced Materials for New Energy Storage and Conversion \\ ${ }^{3}$ Hunan Provincial Key Laboratory of Controllable Preparation and Functional Application of Fine \\ Polymers; Hunan Province College Key Laboratory of QSAR/QSPR \\ "E-mail: $\underline{\text { Song_shs@126.com. }}$
}

doi: $10.20964 / 2020.09 .11$

Received: 1 May 2020 / Accepted: 15 June 2020 / Published: 10 August 2020

Lithium-sulfur (Li-S) batteries have been widely studied in recent years, but the utilization of sulfur cathode is still limited by the low conductivity of cathode material and dissolution of polysulfides. A polypyrrole (PPy) coated reduced graphene oxide/S (RGO/S@PPy) material was synthesized in this study. It is shown that sulfur is uniformly distributed on RGO sheets, and a PPy layer is homogeneously coated on the surface of the RGO/S composite. The PPy coating relieves the dissolution of polysulfides and improves the utilization of active sulfur. As a result, a discharge capacity of $631 \mathrm{~mA} \mathrm{~h} \mathrm{~g}^{-1}$ after 300 cycles at $0.2 \mathrm{C}$ and an excellent rate capability are obtained.

Keywords: Lithium-sulfur battery; Reduced graphene oxide; Polypyrrole; Cycle stability; Rate performance

\section{$\underline{\text { FULL TEXT }}$}

(C) 2020 The Authors. Published by ESG (www.electrochemsci.org). This article is an open access article distributed under the terms and conditions of the Creative Commons Attribution license (http://creativecommons.org/licenses/by/4.0/). 